\title{
2020 Everett Mendelsohn Prize
}

\author{
Karen Rader $^{1} \cdot$ Marsha Richmond $^{2}$
}

Published online: 27 January 2020

(c) Springer Nature B.V. 2020

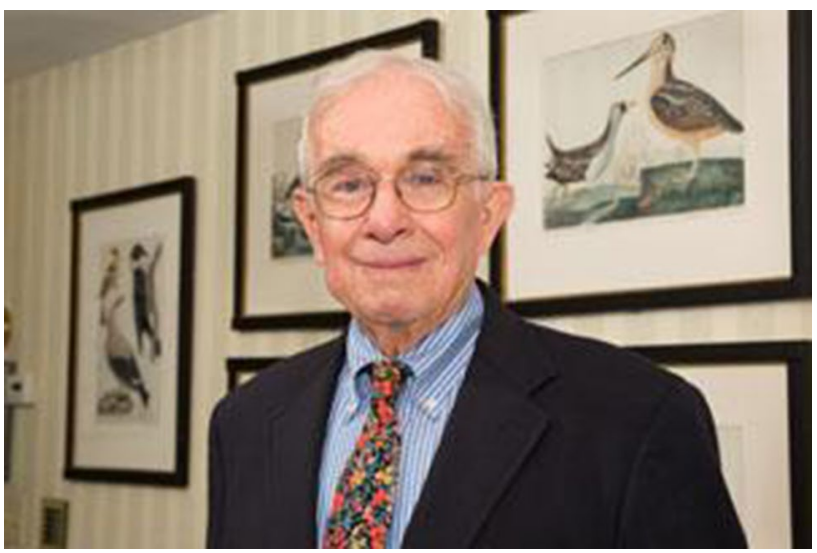

It is our great pleasure to announce that the recipient of the 2020 Everett Mendelsohn Prize is Daniel Liu, whose essay, "The Cell and Protoplasm as Container, Object, and Substance, 1835-1861," appeared in the Journal of the History of Biology, Volume 50, 4 (2017), pp. 889-925.

The Everett Mendelsohn Prize was instituted in 2016 to honor the founding Editor of the Journal of the History of Biology. Everett oversaw JHB's publication for its first 31 years, and in so doing fundamentally shaped the scholarly foundations of the field of the history of biology. The Mendelsohn Prize is awarded annually to the author of an article published in the journal during the previous three years.

For the 2020 award, the prize committee (the Co-Editors-in-Chief and the Associate Editors Luis Campos, Nick Hopwood, and Lynn Nyhart) considered all 65 articles appearing in volumes 50 (2017), 51 (2018), and 52 (2019). The committee judged the entries based on an assessment of originality, scholarship, and

\section{Karen Rader}

journalofthehistoryofbiology@gmail.com

1 Virginia Commonwealth University, Richmond, VA, USA

2 Wayne State University, Detroit, MI, USA 
significance for the history of biology. After considerable discussion, Dan Liu's essay emerged as our top choice. ${ }^{1}$

"The Cell and Protoplasm as Container, Object, and Substance, 1835-1861" addresses an important conceptual and practical problem within nineteenth-century research on cells, a field that has long presented historians with a dilemma. Early contributors who formulated a notion of "the cell" struggled to identify visual and interpretative frameworks for the "fundamental unit of life." But even after improvements in microscope lenses and microtechnique, mid-nineteenth-century observers diverged widely over what they believed these instruments were making visible and over how to interpret their observations. These early "cytologists" struggled to capture accurately the form and function of objects-the cell wall or membrane, the gelatinous interior organ called the "primordial utricle," and the substance, "protoplasm," of which the primordial utricle was made. Liu focuses on the critical three decades in the formulation of modern cell theory, from Schleiden's (and Schwann's) early descriptions of plant and animal cells after 1835 up to Max Schultze's classic redefinition of the cell as a "mass of protoplasm with a nucleus" in 1861.

Liu offers clarity by carefully and meticulously focusing on the work of the major figures in the period, drawing on George Lakoff and Mark Johnson's categorization of material entities (or "ontological metaphors") in Metaphors We Live By (1980). Applying the critical distinctions among "container," "object/entity," and "substance," Liu brings to the fore the essential questions these biologists entertained about whether the material basis of life resided in the cell or in the formless protoplasm they believed generated the cell. In his account, Liu thus explains the important role that Hugo von Mohl played in this debate in focusing on structure as the seat of vitality in his primordial utricle theory of 1844. Yet, as Liu shows, the view of the "sarcode" (or protoplasm) introduced by Félix Dujardin in 1835 gradually supplanted identifying life with structures and shifted biologists' attention to the formless protoplasm as the primary locus of the cell's activity. In careful yet sharp prose, Liu's account provides an analytic clarity that supersedes all previous accounts. The level of empirical mastery as well as theoretical understanding he displays is exceptional, and well warrants his recognition as the recipient of the Mendelsohn Prize.

Daniel Liu is a historian of the modern life and physical sciences, whose scholarship explores how ideas of life and matter have moved across different scientific and cultural domains. He received his PhD in the History of Science, Medicine, and Technology from the University of Wisconsin-Madison in 2016. He was an Andrew W. Mellon Postdoctoral Fellow in Biohumanities at the University of Illinois at Urbana-Champaign, 2016-2018, and a Visiting Postdoctoral Research Fellow at the Max Planck Institute for the History of Science in the summer of 2017. He is currently a fellow at the ICI Institute for Cultural Inquiry in Berlin and working on a book entitled The Physical Bases of Life: Protoplasm, Scientific Microscopy, and Molecular Vision in the Cell's First Century.

\footnotetext{
${ }^{1}$ Nyhart recused herself from voting as Liu's former academic advisor.
} 
On behalf of the 2019 Mendelsohn Prize Committee and Springer-Nature International Publishing, we congratulate Daniel Liu on receiving the 2020 Mendelsohn Prize. Liu's article will be freely available on the Journal of the History of Biology website until April 2020, and he will receive an honorarium of $\$ 500$.

This year's pool of articles was especially rich. As a result, we wish for the first time to recognize two other articles as highly commended.

Jean-Baptiste Grodwohl's virtuoso article “"The Theory was Beautiful Indeed': Rise, Fall and Circulation of Maximizing Methods in Population Genetics (1930-1980)" (JHB 50, 3 [2017]: 571-608) is an involving "biography" of the mean fitness function in population genetics, a modeling method invented in the $1930 \mathrm{~s}$ that was invested with great hope in the late 1950s and early 1960 s, only to succumb to theoretical objections (although it was still adopted in other fields). Rare for its deep research on mathematical methods, this work is enlightening about the uses of mathematics in biology and the tensions between usefulness and reliability. Grodwohl is a Japan Society for the Promotion of Science (JSPS) fellow at SOKENDAI, the Graduate University for Advanced Studies in Hayama.

Mary Mitchell's “Screening Out Controversy: Human Genetics, Emerging Techniques of Diagnosis, and the Origins of the Social Issues Committee of the American Society of Human Genetics, 1964-1973" (JHB 50, 2 [2017]: 425-456) skillfully illuminates an episode in the history of the professionalization of genetics in postwar United States-namely, the formation of the American Society of Human Genetics' Social Issues Committee. Mitchell uses archival evidence and STS concepts to analyze how geneticists framed their public-facing work carefully and deliberately, in ways that undergirded their scientific expertise without embroiling them in the controversial politics of abortion and eugenics. Mitchell is Assistant Professor in the Department of History at Purdue University.

These articles will also be made freely available on the Journal of the History of Biology website until April 2020.

Publisher's Note Springer Nature remains neutral with regard to jurisdictional claims in published maps and institutional affiliations. 